San Antonio Review • San Antonio Review (Issue 2 | Winter 2019)

\title{
Shark Soup
}

\author{
Alex Z. Salinas
}

Published on: Apr 19, 2018

Updated on: Aug 03, 2020

License: Creative Commons Attribution 4.0 International License (CC-BY 4.0). 
I have an irrational fear in the shower when I close my eyes that a shark will burst through the tile wall and devour me whole

Perhaps that's because within the red waters in the chambers of my heart, there lurks a shark with an appetite unceasing till it has swallowed every top floater alive

My heart is encased in shark teeth, is a rubber shield of death impenetrable

Except to you, who pried it open when your lips locked on mine and your tongue searched for sustenance like a hungry shark

My irrational fear is you

Our first kiss every time reminds me every time of your delicious core, which beats like a revolutionary fist, gushes like punctured skin from a mortal wound

And like a good vampire shark, I open my serrated jaws, sink my razor teeth in you, deep in you, my love, past your cream dermis walls till I find that which is all alone,

unprotected

Then I feed from it.

San Antonian Alex Z. Salinas earned a bachelor's degree in political science from St. Mary's University in 2011. His flash fiction has appeared online in Every Day Fiction, Nanoism, escarp, 101 Words, 101 Fiction, and ZeroFlash. He has also had poetry published in the San Antonio Express-News. 